\title{
Friends and Happiness: An Evolutionary Perspective on Friendship
}

\author{
David M. G. Lewis, Laith Al-Shawaf, Eric M. Russell and David M. Buss
}

Friendships are fundamental to human social life. People direct great effort toward both the formation and maintenance of friendships, investing time, energy, money, and emotional resources. Across cultures, friendship is reliably linked to the experience of positive emotions such as happiness (Brannan et al. 2013; Camfield et al. 2009; Chan and Lee 2006; Lu 1995, 1999; for a review see Demir et al. 2013), an association that is present in both same-sex and cross-sex friendships (Argyle 1999), and which holds from early adulthood (Demir and Weitekamp 2007) through old age (Larson et al. 1986). Why are friendships so important to our happiness?

An evolutionary perspective may shed light on this issue. Friendships were almost certainly recurrently linked to survival and reproduction during human evolutionary history, and the specific benefits that accrue to individuals in different types of friendship may offer unique insight into the evolutionary impetuses for these relationships. An evolutionary perspective can offer insight into how specific types of friendship would have benefitted ancestral humans in both the currency of natural selection - reproductive success - and the currency of subjective wellbeing, happiness.

In this chapter, we discuss the relationship between friendship and happiness from an evolutionary perspective by outlining the hypothesized ancestral functions of friendship, and explain why we would expect immersion in such friendships to result in positive emotions such as happiness. We then explore the empirical literature on different friendship types and how each friendship type (e.g., same-sex

D. M. G. Lewis $(\square)$

Psychology Department, Bilkent University, 06800 Ankara, Turkey

e-mail: david.lewis@bilkent.edu.tr

D. M.G. Lewis · L. Al-Shawaf · E. M. Russell · D. M. Buss

The University of Texas at Austin, Austin, USA

E. M. Russell

The University of Texas at Arlington, Arlington, USA

(C) Springer Science+Business Media Dordrecht 2015 
friendship, cross-sex friendship) is characterized by a unique profile of benefits as well as costs. Finally, we propose evolutionarily inspired strategies for individuals to enhance their friendships and maximize the happiness they reap from these important social relationships.

\section{An Evolutionary Approach to Friendship and Happiness}

An evolutionary approach may yield valuable insight into why friendships and immersion in quality social relationships are consistently linked to happiness (Corneau 2009; Demir et al. 2013). It suggests that positive emotions such as happiness are produced by motivational programs that evolved because of their ability to guide ancestral humans to repeat behaviors associated with increased survival and reproductive success (Cosmides and Tooby 2000; Hill et al. 2013; Kenrick et al. 2010). Having friends would have dramatically increased ancestral humans' likelihood of survival and reproduction (Tooby and DeVore 1987). Consequently, selection could have favored mechanisms that produced happiness in response to such friendships to the extent that this subjective experience motivated ancestral humans to form and maintain these beneficial relationships. In the following section, we briefly outline several different evolutionary pathways by which psychological adaptations to form and maintain friendships could have evolved.

\section{Evolutionary Models of Friendship}

\section{Reciprocal Altruism}

Non-evolutionary research has investigated friendship as a means of social exchange in which individuals select friends on the basis of the costs and benefits associated with these friendships (Befu 1977; Emerson 1976; Homans 1958). Although these hypotheses about friend preferences and selection do not articulate the specific benefits exchanged in these friendships, an evolutionary perspective can illuminate how such social exchange relationships could have evolved. The theory of reciprocal altruism postulates that altruistic tendencies toward non-relatives can evolve when the delivery of benefits is reciprocated at some point in the future (Axelrod 1984; Cosmides and Tooby 1992; Trivers 1971). Such exchange relationships can result in net fitness benefits for both parties involved-a condition economists refer to as a "gain in trade" (Kemp 1995). Selection could thus have led to the evolution of mechanisms that motivate individuals to form and maintain these highly beneficial social exchange relationships.

To illustrate how such exchange relationships could have evolved, consider the adaptive problem our ancestors faced of hunting large game to acquire meat. Ancestral humans rarely hunted large game alone due to the risky and costly nature of 
hunting dangerous prey (Milton 1999; Tooby and DeVore 1987). Ancestral humans who formed friendships and coalitions in the service of solving this adaptive problem would have experienced improved survival and reproductive rates, as these coalitions incur fewer costs and enjoy greater success in the hunt for dangerous game (Buss 2004; Hill and Hurtado 1996; Tooby and DeVore 1987). Because individuals who hunted together were more likely to secure nutritious food, over many generations, selection would have favored mechanisms that motivated individuals to form friendships and coalitions to achieve these goals.

The key concept illustrated here is that friendships relationships may have delivered unique sets of benefits linked to ancestral humans' survival and reproduction. It is likely that our ancestors benefitted greatly from these kinds of relationships, and that reciprocal exchange formed the basis not only for many ancestral friendships, but for the mechanisms that lead to friendships in modern environments as well.

\section{The Alliance Model of Friendship}

Another recent evolutionary perspective suggests that human friendship is based on evolved computational systems for building alliances (DeScioli and Kurzban 2012, 2009). The alliance-building model is distinct from the theory of reciprocal altruism, as it is not based on exchange, but rather on concerns about interpersonal conflict. These concerns are a central feature of the alliance-building model, but do not feature prominently in reciprocal altruism models of human friendship.

The central premise of the alliance model is that humans habitually get into conflicts with one another. Having a supportive network of alliances is crucial to successfully navigating these problems and emerging on the "winning" side of direct interpersonal conflicts. Crucially, the likelihood of winning such conflicts depends not only on one's own wit, agility, and physical formidability, but also on one's ability to mobilize other individuals - friends - to support one in such conflicts.

The alliance-building model of friendship proposes that humans have evolved computational systems dedicated to cognitively representing different friends' degree of loyalty to oneself, because those who are most loyal are most likely to provide support in future disputes. DeScioli and Kurzban (2012) insightfully note that "individuals frequently have relationships with both sides in a conflict, particularly because human social networks are locally dense" (p. 216). This suggests that ancestral humans needed to be able to determine whom they would support in any possible pairwise within-group conflict-including one between two close friends. As the authors suggest, one way to do this is to rank one's allies, prioritizing certain friendships over others.

The most important aspect of this hypothesis is that an individual (let's call him Tom) should count among his closest friends those who rank him as one of their closest friends. The logic is that those who consider Tom a very close friend are those who are most likely to be fiercely loyal to him and support him in future 
disputes. This leads to the central prediction derived from the alliance-building hypothesis: other individuals' ranking of Tom should be the strongest predictor of Tom's ranking of these same individuals. By contrast, the reciprocal exchange hypothesis predicts that the friends who provide the largest benefits should be ranked highest. And still other non-evolutionary perspectives contend that the key predictors of friendship rankings will be proximity, similarity, and familiarity (e.g., see Berscheid et al. 1971; Byrne et al. 1968; Singh and Ho 2000).

In three different samples that measured a host of different variables, DeScioli and Kurzban (2009) found that, as predicted, Tom's (perceived) rank in his friends' lists was the strongest predictor of his own friend rankings. Interestingly, consistent but weaker effects were also found for benefits, similarity, and secret-sharing. These findings are intriguing, since they suggest that perceived friendship ranking (which the researchers view as a proxy for loyalty in future disputes) is a more important determinant of friendship closeness than a variety of other predictors put forth by alternative evolutionary and non-evolutionary models. However, the alliance-building and reciprocal exchange hypotheses are not mutually exclusive, and friendship may serve multiple functions.

\section{Positive Externalities}

Although reciprocal exchange may be one viable route for human friendship to evolve, altruism in the context of friendship often appears distinctly non-reciprocal in nature. Some scientists argue against the idea that friendship is based on explicit reciprocity, because many individuals report feeling good assisting a close friend, and report no desire for compensation or future reward (Tooby and Cosmides 1996; DeScioli and Kurzban 2012). Rather, an emphasis on returning favors is indicative of a relationship that is not close; repayment of debts and favors is not characteristic of close friendships (Argyle and Henderson 1984). Consistent with this, people perceive a lack of friendship when someone insists on the return of a favor (Shackelford and Buss 1996). At least at the level of conscious awareness, then, reciprocal altruism is not a defining characteristic of friendship.

Tooby and Cosmides (1996) propose an alternate model for the evolution of friendship mechanisms based on the notion of positive externalities - unintentional benefits that individuals deliver to others without any cost to themselves (Tooby and Cosmides 1996). To illustrate the idea of a positive externality, imagine that you and your friend both need to go to the grocery store, but your friend does not have a car. By allowing your friend to ride along in your car, you provide her with a benefit and yet you incur no additional cost; you were already going to the store. Traditionally, however, this would not be classified as true biological altruism, as the classical definition of the concept of altruism in biology requires that the actor pay a cost in the delivery of benefits to another individual. Tooby and Cosmides (1996) make the insightful point, however, that the less costly it is to deliver benefits to others, the more widespread we should expect such benefit-bestowing behavior to 
be. Furthermore, once benefit-bestowing adaptations of any kind evolved, selection would have refined these adaptations to minimize their costs to the actor (Tooby and Cosmides 1996).

This positive externalities perspective suggests that a large class of altruistic behavior may have thus far gone largely unrecognized and uninvestigated. Indeed, adaptations to deliver or reap the benefits of positive externalities may be woven into the fabric of human friendship, but they remain uncharted territory and represent a fascinating direction for future research.

\section{Mating Opportunities Within Friendships}

Theory and evidence suggest that friends were likely instrumental in helping one another solve a variety of adaptive problems during human evolution, including one particularly close to the engine of natural selection: mating. Indeed, both same- and cross-sex friendships can promote the establishment and maintenance of romantic relationships (see e.g., Bleske and Buss 2000; Connolly et al. 1999; Feiring 1999; Sullivan 1953). Same-sex friends may have played a critical role in helping our ancestors solve adaptive problems related to selecting, attracting, and maintaining mates (Ackerman and Kenrick 2009; Lewis et al. 2011; Lewis et al. 2012), and accumulating evidence suggests that cross-sex friendships hold the potential for both indirectly and directly increasing mating opportunities. Cross-sex friendships provide members of the friendship dyad with information about how the other sex thinks or feels (Bleske and Buss 2000), and can help the sexes better understand each other's communicative style (Swain 1992). Cross-sex friendships sometimes involve casual sexual encounters between members of the dyad, and can even develop into committed long-term mateships.

Indeed, physical attraction within cross-sex friendships is common and often constitutes a significant component of such relationships (O'Meara 1989), and sexual activity in cross-sex friendships is not uncommon (Afifi and Faulkner 2000; Mongeau et al. 2003). The frequency of mating relations within cross-sex friendships, together with the close parallel between mate preferences and cross-sex friend preferences (see Lewis et al. 2011, 2012), suggests that cross-sex friendships may have evolved at least partly for direct mating purposes. We discuss this possibility in detail and present relevant findings later in this chapter.

\section{The Benefits and Costs of Friendship}

Friends provide one another with a bounty of benefits: they offer one another food and other resources, help each other solve problems, provide assistance navigating social hierarchies, and even help solve adaptive problems in the domain of mating. Along with these benefits, however, friendships carry the potential costs of 
competition and rivalry. Friends may inflict costs on one another by competing for access to the same valuable resources, including the same high-quality mates. Their conflicting goals may lead them to interfere with each other's strategies and obstruct each other's path to achieving their objectives, a phenomenon known as strategic interference (Buss 1989; Haselton et al. 2005).

An evolutionary approach to friendship emphasizes the beneficial exchanges that characterize such relationships, but simultaneously points to their potential to impose considerable costs on both parties. The particular profile of costs and benefits differs from friendship to friendship, but also differs markedly from cross-sex to same-sex friendships. Same-sex friendships, for instance, may be hampered by the costs of intrasexual competition for status or mates, whereas cross-sex friendships rarely face this problem. Cross-sex friendships sometimes hold latent potential for mating opportunities, whereas same-sex friendships typically lack this direct benefit. In the sections that follow, we consider the costs and benefits that characterize friendships. We discuss those that are common to same- and cross-sex friendships as well as those that are unique to each distinct friendship type.

\section{Benefits}

\section{Same-Sex Friendship}

Evolutionary research on friendship has yielded novel insights and fascinating findings about the instrumental role friends play in helping one another solve mating-related problems (Ackerman and Kenrick 2009; Lewis et al. 2011). Same-sex friendships provide both men and women with a bounty of benefits directly or indirectly related to mating: communication of sex-related topics between close friends, discussion and analysis of suitors' intentions, the exchange of mating advice, and ultimately, the facilitation of the acquisition of mates (Ackerman and Kenrick 2009; Bleske and Buss 2000; Lefkowitz et al. 2004; Rose 1985).

The link between mating and same-sex friendships leads to a nuanced set of evolutionary predictions about friend preferences. Consider the fact that mate preferences differ between the sexes (Buss and Schmitt 1993), and the well-established principle that the mate preferences of one sex drive competition between members of the other sex (Buss 1988; Trivers 1972). On the basis of these two considerations, we would expect individuals to place a premium on same-sex friends who possess attributes that are simultaneously (a) desirable to the opposite sex, and (b) directly or indirectly transferable to oneself. By choosing same-sex friends who possessed characteristics that are desirable to the opposite sex, ancestral individuals could have experienced beneficial spillover effects. Moreover, if these desirable traits were also transferable to oneself, the benefits would have been further amplified.

Consider the following example. Because men value physical attractiveness in their long-term mates more than do women (Buss 1989; Buss and Schmitt 1993; Li et al. 2002), women may have secured greater fitness-related benefits by forming 
and maintaining friendships with physically attractive members of their own sex. In this way, less attractive women could have benefitted from the newfound proximity of eligible, high-quality males. This magnitude of this benefit would have been further amplified to the extent that physical attractiveness is a transferable resourcefor instance, if befriending an attractive same-sex other helps an individual improve her own physical attractiveness through fitness or beauty-related advice.

Similarly, because women value men who command economic resources, we should expect men to have a strong preference for same-sex friends with resources (Vigil 2007). That is, an evolutionary perspective on same-sex friendship predicts that men will be inclined to befriend other men who are in control of such resources, as these friends would have been valuable in helping to enhance one's mating opportunities. Moreover, economic resources represent a highly transferable desirable attribute, so men may derive especially large benefits from befriending individuals who are both wealthy and generous.

Lewis and colleagues (2011) found support for these predictions. This research team employed a budget allocation task in which men and women designed their ideal same-sex friends by allocating "friend dollars" to six categories of traits (e.g. Economic Resource Status, Physical Attractiveness, Personality). As predicted, men placed greater value on characteristics in same-sex friends related to status elevation and resource acquisition. Research in this area is just beginning, but these results provide preliminary support for the idea that humans value characteristics in same-sex friends that would have facilitated the solution of sex-specific adaptive problems in ancestral environments. As we might expect, this valuation appears to be amplified when the traits in question are directly or indirectly transferable to oneself.

\section{Cross-Sex Friendship}

Cross-sex friendships also carry great fitness benefits, but they differ in nature from those associated with same-sex friendship. Cross-sex friends can offer benefits that same-sex friends cannot provide. For example, consider the pronounced human sexual dimorphism in muscle mass and upper body strength (Lassek and Gaulin 2008; Lassek and Gaulin 2009). This sex difference in physical strength suggests that on average, ancestral women would have derived the benefits of much more effective physical protection by befriending a physically formidable man rather than another woman.

Direct mating opportunities represent another important class of benefits uniquely afforded by cross-sex friends. Indeed, the reported benefits of cross-sex friendship (Bleske and Buss 2000) correspond closely to the attributes that men and women desire in mates (Buss and Schmitt 1993). This correspondence between mate preferences and the benefits of cross-sex friendship suggests that the psychological mechanisms that motivate cross-sex friendship may be at least partially underpinned by men's and women's evolved mating strategies. 
Sexual strategies theory (Buss and Schmitt 1993) provides a principled theoretical framework for making a priori predictions about sex differences and similarities in men and women's mating strategies. Men and women are predicted to have similar mate preferences in those domains in which they faced the same adaptive problems, and divergent mate preferences in those domains in which they faced different adaptive problems (e.g. internal fertilization and gestation, paternity uncertainty, age-related fertility decline, etc.). For instance, both men and women place a premium on long-term mates who are kind, cooperative, and trustworthy (Buss 2003). However, sex differences in adaptive problems have led to sex differences in mate preferences: men and women differentially prioritize characteristics such as resource acquisition potential and physical attractiveness (Buss and Schmitt 1993).

Cross-sex friend preferences follow strikingly similar sex-differentiated patterns. For example, men show a stronger preference than women for physically attractive cross-sex friends, whereas women exhibit a stronger desire for cross-sex friends who are successful at acquiring economic resources and are able to provide protection through physical strength and athleticism (Lewis et al. 2011). This striking overlap between cross-sex friend preferences and mate preferences hints at the tantalizing possibility that the initiation and maintenance of cross-sex friendships may involve the activation of mating mechanisms.

If mating psychology plays a part in cross-sex friendship, then we should be able to detect the signature of mating activation in cross-sex friend preferences. Specific predictions follow from this mating activation hypothesis in cross-sex friendships (Lewis et al. 2012). The mating activation hypothesis predicts that individual differences that influence the costs and benefits of directing mating effort toward crosssex friends should predict cross-sex friend preferences (Lewis et al. 2012).

One such individual difference variable is sociosexual orientation. Sociosexual orientation describes an individual's attitudinal, cognitive, and behavioral inclination toward uncommitted sex (Penke and Asendorpf 2008; Simpson and Gangestad 1991). Reasoning that individuals with an "unrestricted" sociosexual orientationa greater proclivity for engaging in uncommitted sexual relations - would derive greater net benefits from pursuing a mating strategy with cross-sex friends, Lewis and colleagues (2012) predicted that the degree of similarity between cross-sex friend preferences and mate preferences would be directly linked to individuals' sociosexual orientation. This prediction was confirmed for both sexes. Among both men and women, an unrestricted sociosexual orientation predicted the prioritization of cross-sex friends' physical attractiveness, and among women only, an unrestricted sociosexual orientation predicted the prioritization of physical prowess in their male friends (Lewis et al. 2012). This striking parallel with mate preferences suggests that unrestricted individuals prefer cross-sex friends who possess precisely those characteristics desired in mates. These findings contribute to the growing body of friendship literature by indicating that cross-sex friendship formation may be partly underlain by the activation of mating psychology. Moreover, cross-sex friend preferences may partly depend on individual difference variables that influence the costs and benefits of engaging in mating behavior with cross-sex friends. 
Research suggests that many of the benefits of cross-sex friendships are enduring across the lifespan. This is true, for example, of companionship, emotional or financial support, advice, understanding the perspectives of the opposite sex, and fun and laughter (Bleske-Rechek et al. 2012). However, future research is needed to understand how cross-sex friendships change as individuals age, and how the benefits of cross-sex friendship differ across life stages, including with reproductive maturity and marital or mated status. Little is known specifically about the crosssex friendships of middle-aged adults, for example (Monsour 2002), but preliminary investigations in this area suggest that the benefits of cross-sex friendships do shift across the lifespan. For example, older adults are more likely to cite enhanced confidence and improved self-esteem as important benefits of cross-sex friendships (Bleske-Rechek et al. 2012).

\section{Costs}

\section{Same-Sex Friendship}

Same-sex friends help each other navigate the exigencies of life. However, both men and women perceive same-sex friendship as carrying the potential for costly intrasexual rivalry (Bleske and Buss 2001). Despite the various benefits that samesex friends receive from each other (e.g. companionship, status enhancement, access to a larger pool of mates; Bleske and Buss 2000; Lewis et al. 2011; Rose 1985), same-sex friends also experience competition with one another in the pursuit of high-quality mates (Bleske and Buss 2000; Bleske and Shackelford 2001; Buss 2003). Intrasexual competition and rivalry in same-sex friendships may even be influential enough to elicit feelings of betrayal (Shackelford and Buss 1996) and result in the dissolution of friendships (Bleske and Shackelford 2001).

\section{Cross-Sex Friendship}

Cross-sex friendships can impose tremendous costs as well. Cross-sex friendships can suffer from unwanted sexual attraction (DeSouza et al. 1992), and unwanted sexual overtures can result in tension, awkwardness, and harassment (Browne 2006). Some people feel that their cross-sex friends misinterpret their friendliness as romantic or sexual interest (Elsesser and Peplau 2006), and while cross-sex friendships are linked to mating-related benefits for some individuals, sexual attraction is seen as a challenge between close cross-sex friends (Halatsis and Christakis 2009). Importantly, sexual attraction is more often nominated as a cost than as a benefit of cross-sex friendships (Bleske-Rechek et al. 2012).

These costs are especially problematic for women in cross-sex friendships. Because men have a strong desire to gain sexual access to women, derive greater 
fitness benefits from casual sexual liaisons (Buss 1994), and perceive sexual access to be a greater benefit of cross-sex friendship than do women (Bleske and Buss 2000), men may initiate unwanted sexual advances toward their cross-sex friends. Men experience greater physical attraction toward their cross-sex friends than do women (Kaplan and Keys 1997; Bleske-Rechek et al. 2012), are more likely than women to endorse the statement "there was a time when I wanted to be more than just friends with [my closest cross-sex friend]", and are more likely to initiate a cross-sex friendship with the hope of it developing into a romance (Kaplan and Keys 1997). Men's mating cognition is also influenced by a bias to interpret friendly female greetings as sexual interest, and to infer sexual intent where there is none (the male sexual overperception bias, Haselton and Buss 2000; Haselton and Nettle 2006; Abbey 1982; Abbey and Melby 1986). Research suggests that this male cognitive bias extends into men's cross-sex friendships (Bleske-Rechek et al. 2012).

From an evolutionary perspective, it can be very costly for a woman to remain in a cross-sex friendship in which she is the target of unwanted sexual advances. Women who find themselves in such situations may suffer severe emotional, energetic, and reproductive costs. Moreover, a close friendship with a sexually interested male can jeopardize a woman's chances of finding a mate who is assured of her fidelity and willing to invest in and commit to her (Buss 1994). For women who are already mated, close cross-sex friendships may inspire suspicion and jealousy from one's mate. This can have a detrimental impact both on the relationship and on the woman's safety, as men's sexual jealousy in particular is a powerful predictor of such costly outcomes as spousal abuse, intimate partner violence, and uxoricide (Buss 2005; Daly et al. 1982; Wilson and Daly 1992, 1996, 1998).

Women certainly suffer the brunt of the sexual costs of cross-sex friendships, but men also report incurring costs in this domain. Men are more likely than women to report that their cross-sex friends have led them on sexually (Bleske-Rechek and Buss 2001) _ an outcome that may be attributable to the frequent asymmetry in sexual interest between men and women coupled with the male sexual overperception bias. Men and women alike also perceive attraction in cross-sex friendships as burdensome, and as a potential threat to their long-term mateships (Bleske-Rechek et al. 2012).

Some of the costs of cross-sex friendship are constant across the lifespan, whereas others differ across life stages, partly as a function of changes in age and marital status. Many of the cost categories nominated by individuals in cross-sex friendships are shared across age categories. These include sexual attraction and interactions that are deemed to be stressful or emotionally draining (Bleske-Rechek et al. 2012). Before reaching sexual maturity, however, females perceive their cross-sex friendships to be less significant (Lempers and Clark-Lempers 1993). The spike in the importance of cross-sex friendships after reproductive maturity may heighten both the costs and the benefits of such relationships for women.

At later life stages, the costs of cross-sex friendships such as "takes time away from my family life" and "my romantic partner gets jealous of our friendship" are nominated at higher frequencies (Bleske-Rechek et al. 2012). Married individuals also have less contact with and confide less in their cross-sex friends, and the 
number of cross-sex friends that women maintain decreases with age (Booth and Hess 1974). An evolutionary perspective suggests that cross-sex friendship likely poses different adaptive challenges as a function of an individual's life history phase, and that human friendship psychology may be attuned to the changing nature of cross-sex friendship over the lifespan. This context-driven and lifespan-dependent nature of the costs of cross-sex friendship remains a relatively uninvestigated area of scholarship, and an exciting avenue for future research.

\section{Friendships and Maximizing Happiness}

Friendship quality is predictive of happiness across age groups and cultures (Brannan et al. 2013; Chan and Lee 2006; Demir et al. 2013; Holder and Coleman 2009; Hussong 2000). However, because the members of a friendship dyad frequently have conflicting goals, such relationships often result in the intentional or unintentional obstruction of one another's goals. This strategic interference (Buss 1989) underscores the potential for intrasexual and intersexual competition in human friendship, and highlights the unfortunate fact that friendships can often lead to negative experiences such as conflict (Hartup et al. 1988; Laursen 1995), rivalry (Berndt 2002), and even betrayal (Shackelford and Buss 1996).

We think that an evolutionary perspective can shed unique light on how humans may be able to reap the benefits of friendships while simultaneously minimizing the costs such relationships impose. Future research would profit from an investigation of the specific costs and benefits of friendship that affect overall happiness, but at present it seems safe to infer that the costs inherent in friendships have a negative impact on the relationship and resultant happiness levels. In this section, we share evolutionarily inspired ideas for enhancing friendships and maximizing their happiness yield.

Close meaningful friendships are often hampered by the costs that such dyadic relationships can impose. But what if these costs were absent? Might it be possible, for example, for an individual's friendships to be free of intrasexual rivalry and sexual deception? Research suggests that friendships that cross sexual orientation may be unique in this regard (Grigoriou 2004; Hopcke and Rafaty 1999). Specifically, friendships between heterosexual women and homosexual men may enable the beneficial exchange of mating-related benefits without the potential for the typical costs that plague heterosexual same- and cross-sex friendships (Russell et al. 2013).

This friendship type is distinct from other friendships, because heterosexual women and homosexual men are neither rivals in the mating domain nor potential romantic partners. In the absence of intrasexual mating rivalry and concealed mating motivations, these friendships are often marked by a level of trust and support not found in other types of friendship (Grigoriou 2004; Hopcke and Rafaty 1999; Malone 1980). It is heartening to find that friendships free of these costs are associated with such positive relationship outcomes. In this light, we suggest strategies that individuals can follow in order to increase the benefits and happiness they can 
draw from their friendships while simultaneously minimizing the costs of competition, deception, and strategic interference.

\section{The Banker's Paradox and Becoming Irreplaceable}

Just as banks prefer to lend money to people with minimal credit risk, and are least likely to provide loans to those who are most in need, we might expect humans to be (paradoxically) least likely to invest in individuals in their hour of greatest need-when they are sick, have poor prospects, or otherwise appear unlikely to be able to return the favor in the future. The banker's paradox describes this social dilemma: it is profitable to invest in others who are in good condition and are able to return benefits, and to discount the needs of those who are in poor condition and least likely to be able to repay the actor in the future. This unfortunate payoff matrix would have led our ancestors to avoid precisely those who required the most help. The consequence of this logic is that the ruthless currency of selection would have favored psychological mechanisms that led individuals to desert each other during times of dire need. In short, the banker's paradox predicts that people may be least likely to befriend or help those who are poor credit risks - those that show the greatest signs of urgent need (Tooby and Cosmides 1996).

One key solution to this problem may be for individuals to strive to become irreplaceable and indispensable to their friends (Tooby and Cosmides 1996). Tooby and Cosmides (1996) illustrate several strategies by which an individual might become irreplaceable. For example, one can promote a reputation that highlights one's unique or exceptional attributes, cultivate specialized skills possessed by no one else within one's social group, demonstrate one's unwavering loyalty, or avoid social groups in which one's unique attributes are not valued. Cultivating a unique set of skills or benefits that nobody else in one's in-group possesses may be critical to the solution of the banker's paradox, as it dramatically lowers the likelihood of desertion in times of vulnerability and despair (Tooby and Cosmides 1996).

\section{Developing Close Friendships}

An effective strategy for maximizing happiness in friendships may be to invest in deep, close friendships. Individuals who succeed in establishing a deep bond with a friend may be much more likely to receive critical aid during times of need. Tooby and Cosmides (1996) argue this position cogently, distinguishing between true friends and fair-weather friends. The adaptive problem of distinguishing your true friends from your fair-weather friends is not an easy one, as fair-weather friends appear deceptively similar to true friends when circumstances are favorable and conditions are auspicious. Unfavorable circumstances in which one friend is in need of help that would be costly for the other friend to deliver provide the litmus test for 
friendships. Because these harsh times would have been critical for ancestral humans' survival and reproduction, we should expect selection to have fashioned psychological mechanisms that are acutely sensitive to the behavior that one's friends exhibit under such circumstances.

Distinguishing between fair-weather friends and true friends is a critical issue that has received very little attention in the literature, and represents an exciting direction for future friendship research. In line with Tooby and Cosmides (1996), we suggest that cultivating true friendships, those characterized by deep engagement, is of paramount importance in deriving deep satisfaction from social relationships. Individuals who emphasize these close friendships can put themselves in a position to reap the security, support, and happiness that these kinds of friendships are uniquely positioned to deliver. In our view, individuals who wish to maximize the benefits and happiness they can harvest from their friendships should allocate time and effort to developing close, deep friendships over superficial friend networks, and should invest seriously in establishing bonds of loyalty and trust.

\section{Managing Intrasexual Rivalry}

Managing intrasexual rivalry is likely a critical path to minimizing the costs of same-sex friendships. Humans display a rich array of strategies designed to compete with same-sex others for desirable mates, resources, and positions in the status hierarchy. These tactics include competitor derogation and manipulation (Buss and Dedden 1990; Fisher and Cox 2010), exaggerated self-enhancement, and spreading rumors about intrasexual rivals (Buss and Dedden 1990). Unfortunately, these same strategies sometimes manifest themselves within same-sex friendships.

Individuals in same-sex friendships stand to benefit greatly by communicating and promoting positive reciprocity in order to prevent unnecessary competition and rivalry (Axelrod 1984). Such reciprocity facilitates cooperative strategies and inhibits the activation of competitive or exploitative strategies, partly because it results in positive feedback loops of cooperation and lowers the payoff of exploitative strategies (Axelrod 1984). If competitive strategies are successfully inhibited, goal obstruction and strategic interference are kept to a minimum, and the resultant stress and negative emotions are consequently minimized as well.

Cooperative exchange in friendships can be further facilitated if each party insists on no more than equity (Axelrod 1984). Because greed, trying to extract more than one's fair share of benefits, is a downfall in many relationships, setting equity as a goal may help prevent the negative emotions that arise in response to one partner taking more than his fair share of the pair's pooled resources. This type of strategy may be helpful in minimizing conflict and feelings of betrayal or injustice. In this way, employing the principles of fairness and reciprocity that have been integral to the evolution of human cooperativeness will likely prove to be instrumental in minimizing conflict and strife and promoting harmony in friendships. 


\section{Minimizing Envy}

Minimizing envy may be key for enjoying greater happiness in friendships, as envy is inversely related to happiness (Belk 1984). Same-sex friends can vastly reduce the potential for envy by developing friendships with others who are similar in values, interests, personality, and, importantly, mate value. A growing body of research suggests that women who develop friendships with more attractive same-sex friends experience greater envy and feel the need to derogate their attractive friends (Bleske-Rechek and Lighthall 2010; Fisher and Cox 2009). Although women may be able to gain otherwise unattainable access to men of higher mate value by consorting with more attractive same-sex friends, they may also be undermining their chances for a close, deep friendship if envy is inextricably intertwined with such benefits. Developing same-sex friendships with individuals of similar mate value, on the other hand, may diminish this envy and result in greater emotional closeness between friends as well as increased happiness.

The optimal balance in such tradeoffs will depend on the characteristics of the individual and of the context. Awareness of these issues, however, is sure to be an important building block for mindfully managing these costs. It may also serve individuals well to identify the benefits that they can offer to their same-sex friends and that their friends can offer them, and then to develop courses of action for delivering and attaining these benefits without inducing envy (Hill and Buss 2008).

\section{Allowing for Communication}

Fostering open communication is another key strategy for reducing strife and maximizing happiness in friendships. This strategy may be especially useful in crosssex friendships, in which the different parties often have different intentions and expectations.

Although some cross-sex friendships are characterized by mutual sexual attraction, men and women differ in their motivations for forming cross-sex friendships (Bisson and Levine 2009; Bell 1981; Lehmiller et al. 2011). Men are typically more strongly motivated by sexual desire in their formation of these relationships, and perceive having sex with their female friends as a benefit of cross-sex friendships (Bleske and Buss 2000). Women, on the other hand, are more strongly motivated by the desire for an emotional connection in their friends with benefits relationships (Lehmiller et al. 2011). This suggests that men and women likely evaluate the benefits of friends with benefits relationships differently. The common asymmetry in sexual desire, together with men and women's conflicting priorities in such relationships, hold great potential for disappointment and discord. It is perhaps not surprising, then, that some friends who develop a sexual relationship report positive effects on their friendship quality, whereas others report considerable relational damage as a result of their sexual liaison (Afifi and Faulkner 2000). 
Investigating these sex-differentiated mating motivations will be important for enhancing our understanding of how friends with benefits relationships can improve relational quality (Afifi and Faulkner 2000) and contribute to each party's happiness, as well as the unique obstacles and risks such relationships can pose. Afifi and Faulkner (2000) suggest that individuals who engage in friends with benefits relationships should emphasize an open flow of communication in which both parties discuss the meaning of sexual activity within their relationship. Doing so will likely reduce friction and make the experience more pleasurable, increasing happiness and satisfaction within the dyad (Cooper and Stoltenberg 1987). If friends do not take an active role in resolving discrepant desires and expectations through open communication, the friendship may suffer from dishonesty, inaccurate inference of the other sex's intentions, and even deception designed to fulfill one's own desires (Haselton et al. 2005). On the other hand, by promoting an open flow of communication about each individual's hopes and expectations for the friendship, cross-sex friends can reduce a major source of conflict in their relationships and enjoy the benefits of a close friendship without the adverse impact of uncertainty, strategic interference, and outright deception.

\section{Conclusions}

An evolutionary perspective provides a functional approach to the science of friendship and our understanding of its link to happiness. This perspective draws attention to the unique profiles of costs and benefits that characterize each type of friendship, and serves as a useful heuristic for investigating areas as diverse as friendship initiation, conflict and discord, relationship dissolution, the predictors of individual differences in friendships, and the activation of mating mechanisms in cross-sex friendships. Evolutionary research on friendship is still in its nascent stages, but the available literature already offers valuable insight into the costs and benefits of friendship, the functions of each friendship type, and individual differences within these friendships.

In light of the various fitness-benefits and challenges that characterize different types of friendship, an evolutionary perspective may be instructive in suggesting ways for individuals to reduce discord and enhance the happiness yield of their friendships. For example, because of the pervasive problems associated with competing for the same mates, same-sex friendships between heterosexual women or heterosexual men may be maligned by deception and distrust. Awareness of these costs is the first step in mitigating them and moving toward a happier friendship. However, individuals in those fortunate cross-sex friendships that are not burdened by unrequited sexual interest (such as friendships between heterosexual women and gay men; Russell et al. 2013) report feeling particularly fulfilled (Hopcke and Rafaty 1999). A particularly fruitful direction for future research may be to explore how people can mitigate or even completely eschew the costs of friendship (e.g., 
mating competition in same-sex friendships and deceptive sexual intent in cross-sex friendships) in the service of promoting relationship harmony and happiness.

Exploring friendship from an evolutionary perspective enables us to bring a principled theoretical paradigm to bear on these issues, and to situate friendship within a larger framework of biological conflict and cooperation. Evolutionary approaches to friendship simultaneously hold great promise for the basic science of social relationships, as well as the practical objective of enhancing our close relationships. Evolutionarily inspired strategies for maximizing the happiness yield of friendships are tailored to specific friendship types, but the common thread underlying all of these recommendations is increased awareness. A critical first step to deepening and enhancing friendships is an awareness of the potential problems that such relationships can pose. One of the great virtues of an evolutionary approach to friendship is that it can arm us with this knowledge, which represents the first step to reducing the strife and discord in our relationships. In so doing, we can clear the path to an enhanced sense of joy and satisfaction in our friendships. It is our hope that this chapter makes a modest contribution to these goals, and helps researchers progress toward a comprehensive science of this fundamental social relationship and its relation to human happiness.

\section{References}

Abbey, A. (1982). Sex differences in attributions for friendly behavior: Do males misperceive females' friendliness? Journal of Personality and Social Psychology, 32, 830-838. doi:10.1037/0022-3514.42.5.830.

Abbey, A., \& Melby, C. (1986). The effect of nonverbal cues on gender differences in perceptions of sexual intent. Sex Roles, 15, 283-298. doi:10.1007/BF00288318.

Ackerman, J. M., \& Kenrick, D. T. (2009). Cooperative courtship: Helping friends raise and raze relationship barriers. Personality and Social Psychology Bulletin, 35, 1285-1300. doi:10.1177/0146167209335640.

Afifi, W. A., \& Faulkner, S. L. (2000). On being 'just friends': The frequency and impact of sexual activity in cross-sex friendships. Journal of Social and Personal Relationships, 17, 205-222. doi: $10.1177 / 0265407500172003$.

Argyle, M. (1999). Causes and correlates of happiness. In D. Kahneman, E. Diener, \& N. Schwarz (Eds.) Well-being: The foundations of hedonic psychology (pp. 353-373). New York: Russell Sage Foundation. http://www.mendeley.com/catalog/causes-correlates-happiness/. Accessed 17 Dec 2014.

Argyle, M., \& Henderson, M. (1984). The rules of friendship. Journal of Social and Personal Relationships, 1, 211-237. doi:10.1177/0265407584012005.

Axelrod, R. (1984). The evolution of cooperation. New York: Basic Books. http://www.amazon. com/Evolution-Cooperation-Revised-Robert-Axelrod/dp/0465005640. Accessed 17 Dec 2014.

Befu, H. (1977). Social exchange. Annual Review of Anthropology, 6, 255-281. doi:10.1146/annurev.an.06.100177.001351.

Bell, R. R. (1981). Friendships of women and men. Psychology of Women Quarterly, 5, 402-417.

Belk, R. W. (1984). Three scales to measure constructs related to materialism: Reliability, validity, and relationships to measures of happiness. Advances in Consumer Research, 11, 291-297. doi:10.1177/0092070306289291. 
Berscheid, E., Dion, K., Walster, E., \& Walster, G. W. (1971). Physical attractiveness and dating choice: A test of the matching hypothesis. Journal of Experimental Social Psychology, 7, 173-189. doi:10.1177/0146167286124001.

Bisson, M. A., \& Levine, T. R. (2009). Negotiating a friends with benefits relationship. Archives of Sexual Behavior, 38, 66-73. doi:10.1007/s10508-007-9211-2.

Bleske, A. L., \& Buss, D. M. (2000). Can men and women be just friends? Personal Relationships, 7, 131-151. doi:10.1177/01461672012710007.

Bleske, A. L., \& Buss, D. M. (2001). Opposite-sex friendship: Sex differences and similarities in initiation, selection, and dissolution. Personality and Social Psychology Bulletin, 27, $1310-1323$.

Bleske, A. L., \& Shackelford, T. K. (2001). Poaching, promiscuity, and deceit: Combating mating rivalry in same- sex friendships. Personal Relationships, 8, 407-424. doi:10.1111/j.1475-6811.2001.tb00048.x.

Bleske-Rechek, A. L., \& Buss, D. M. (2001). Cross sex friendship: Sex differences and similarities in initiation, selection, and dissolution. Personality and Social Psychology Bulletin, 27, 1310-1323. doi:10.1177/01461672012710007.

Bleske-Rechek, A., \& Lighthall, M. (2010). Attractiveness and rivalry in women's friendships with women. Human Nature, 21, 82-97. doi: 10.1007/s12110-010-9081-5.

Bleske-Rechek, A., Sommers, E., Micke, C., Erickson, L., Matteson, L., Stocco, C., Schumacher, B., \& Ritchie, L. (2012). Benefit or burden? Attraction in cross-sex friendship. Journal of Social and Personal Relationships, 29, 569-596. doi: 10.1177/0265407512443611.

Booth, A., \& Hess, E. (1974). Cross-sex friendship. Journal of Marriage and Family, 36, 38-47. doi:10.2307/350992.

Brannan, D., Biswas-Diener, R., Mohr, C. D., Mortazavi, S., \& Stein, N. (2013). Friends and family: A cross-cultural investigation of social support and subjective well-being among college students. The Journal of Positive Psychology, 8, 65-75. http://dx.doi.org/10.1080/17439760.2 012.743573. Accessed 17 Dec 2014.

Browne, K. R. (2006). Sex, power, and dominance: The evolutionary psychology of sexual harassment. Managerial and Decision Economics, 27, 145-158. doi:10.1002/mde.1289.

Berndt, T. J. (2002). Friendship quality and social development. Current Directions in Psychological Science, 11, 7-10. http://dx.doi.org/10.1111/1467-8721.00157. Accessed 17 Dec 2014.

Buss, D. M. (1988). The evolution of human intrasexual competition: Tactics of mate attraction. Journal of Personality and Social Psychology, 54, 616-628. doi:10.1037/0022-. 3514.54.

Buss, D. M. (1989). Conflict between the sexes: Strategic interference and the evocation of anger and upset. Journal of Personality and Social Psychology, 56, 735-747. doi:10.1037/00223514.56.5.735.

Buss, D. M. (1994). The strategies of human mating. American Scientist, 82, 238-249. http://www. jstor.org/stable/29775193. Accessed 17 Dec 2014.

Buss, D. M. (1994/2003). Evolution of desire. New York: Basic Books. http://www.ebook3000. com/The-Evolution-Of-Desire_89872.html. Accessed 17 Dec 2014.

Buss, D. M. (2004). Evolutionary psychology: The new science of the mind (4th ed.). Boston: Allyn and Bacon. http://booksgreatchoice.com/getbook/p304099/?id=30. Accessed 17 Dec 2014.

Buss, D. M. (2005). The murderer next door: Why the mind is designed to kill. New York: Penguin. http://www.goodreads.com/book/show/488723.The_Murderer_Next_Door. Accessed 17 Dec 2014.

Buss, D. M., \& Dedden, L. A. (1990). Derogation of competitors. Journal of Social and Personal Relationships, 7, 395-422. doi:10.1177/0265407590073006.

Buss, D. M., \& Schmitt, D. P. (1993). Sexual strategies theory: An evolutionary perspective on human mating. Psychological Review, 100, 204-232. doi:10.1037/0033-295X.100.2.204.

Byrne, D., London, O., \& Reeves, K. (1968). The effects of physical attractiveness, sex, and attitude similarity on interpersonal attraction. Journal of Personality, 36, 259-271. doi:10.1111/j.1467-6494.1968.tb01473.x.

Camfield, L., Choudhury, K., \& Devine, J. (2009). Well-being, happiness and why relationships matter: Evidence from Bangladesh. Journal of Happiness Studies, 10, 71-91. doi:10.1007/ s10902-007-9062-5. 
Chan, Y. K., \& Lee, R. P. L. (2006). Network size, social support and happiness in later life: A comparative study of Beijing and Hong Kong. Journal of Happiness Studies, 7, 87-112. http:// dx.doi.org/10.1007/s10902-005-1915-1. Accessed 17 Dec 2014.

Connolly, J., Craig, W., Goldberg, A., \& Pepler, D. (1999). Conceptions of cross sex friendships and romantic relationships in early adolescence. Journal of Youth and Adolescence, 28, 481494. doi:10.1023/A:1021669024820.

Cooper, A., \& Stoltenberg, C. D. (1987). Comparison of sexual enhancement and communication training program on sexual and marital satisfaction. Journal of Consulting Psychology, 34, 309-314. doi:10.1037/0022-0167.34.3.309.

Corneau, A. (2009). Doctoral student social support and satisfaction with life. Dissertation Abstracts International, 69. http://gradworks.umi.com/33/20/3320378.html. Accessed 17 Dec 2014.

Cosmides, L., \& Tooby, J. (1992). Cognitive adaptations for social exchange. In J. Barkow, L. Cosmides, \& J. Tooby (Eds.), The adapted mind (pp. 163-228). New York: Oxford University Press. http://www.cep.ucsb.edu/papers/Cogadapt.pdf. Accessed 17 Dec 2014.

Cosmides, L., \& Tooby, J. (2000). Evolutionary psychology and the emotions. In M. Lewis \& J. M. Haviland-Jones (Eds.), Handbook of emotions (2nd ed., pp. 91-115). New York: Guilford. http://www.cep.ucsb.edu/papers/Emotions.pdf. Accessed 17 Dec 2014.

Daly, M., Wilson, M., \& Weghorst, S. J. (1982). Male sexual jealousy. Ethology and Sociobiology, 3, 11-27. doi:10.1016/0162-3095(82)90027-9.

Demir, M., Orthel, H., \& Andelin, A. K. (2013). Friendship and happiness. In S. A. David \& I. Boniwell (Eds.) Oxford handbook of happiness (pp. 860-870). New York: Oxford University Press. http://www.axon.es/axon/LibroFicha.asp?Libro=94159\&T=THE+OXFORD+HANDB OOK+OF+HAPPINESS. Accessed 17 Dec 2014.

Demir, M., \& Weitekamp, L. A. (2007). I am so happy 'cause today I found my friend: Friendship and personality as predictors of happiness. Journal of Happiness Studies, 8, 181-211. doi:10.1007/s10902-006-9034-1.

DeScioli, P., \& Kurzban, R. (2009). The alliance hypothesis for human friendship. Public Library of Science ONE, 4(6), e5802. doi:10.1371/journal.pone.0005802.s001

DeScioli, P., \& Kurzban, R. (2012). The company you keep: Friendship decisions from a functional perspective. In J. I. Krueger (Ed.), Social judgment and decision making (pp. 209-225). New York: Psychology Press. http://www.amazon.com/Social-Judgment-Decision-FrontiersPsychology/dp/1848729065. Accessed 17 Dec 2014.

DeSouza, E. R., Pierce, T., Zanelli, J. C., \& Hutz, C. (1992). Perceived sexual intent in the U.S. and Brazil as a function of nature of encounter, subjects' nationality, and gender. Journal of Sex Research, 29, 251-260. doi:10.1080/00224499209551645.

Elsesser, K., \& Peplau, L. A. (2006). The glass partition: Obstacles to cross-sex friendships at work. Human Relations, 59, 1077-1100. doi:10.1177/0018726706068783.

Emerson, R. M. (1976). Social-exchange theory. Annual Review of Sociology, 2, 335-362. doi:10.1146/annurev.so.02.080176.002003.

Feiring, C. (1999). Other-sex friendship networks and the development of romantic relationships in adolescence. Journal of Youth and Adolescence, 28, 495-512. doi:10.1023/A:1021621108890.

Fisher, M., \& Cox, A. (2009). The influence of female attractiveness on competitor derogation. Journal of Evolutionary Psychology, 7, 141-155. doi:10.1556/JEP.7.2009.2.3.

Fisher, M., \& Cox, A. (2010). Four strategies used during intrasexual competition for mates. Personal Relationships, 18, 20-38. doi:10.1111/j.1475-6811.2010.01307.x.

Grigoriou, T. (2004). Friendship between gay men and heterosexual women: An interpretive phenomenological analysis. London: London South Bank University, Families and Social Capital ESRC Research Group. http://www.lsbu.ac.uk/ahs/downloads/families/familieswp5.pdf. Accessed 17 Dec 2014.

Halatsis, P., \& Christakis, N. (2009). The challenge of sexual attraction within heterosexuals' cross-sex friendship. Journal of Social and Personal Relationships, 26, 919-937. doi:10.1177/0265407509345650.

Hartup, W. W., Laursen, B., Stewart, M. I., \& Eastenson, A. (1988). Conflict and the friendship relations of young children. Child Development, 59, 1590-1600. doi:10.2307/1130673. 
Haselton, M. G., \& Buss, D. M. (2000). Error management theory: A new perspective on biases in cross-sex mind reading. Journal of Personality and Social Psychology, 78, 81-91. doi:10.1037110022-3514.78.1.81.

Haselton, M. G., \& Nettle, D. (2006). The paranoid optimist: An integrative evolutionary model of cognitive biases. Personality and Social Psychology Review, 10, 47-66. doi:10.1207/ s15327957pspr1001_3.

Haselton, M., Buss, D. M., Oubaid, V., \& Angleitner, A. (2005). Sex, lies, and strategic interference: The psychology of deception between the sexes. Personality and Social Psychology Bulletin, 31, 3-23. doi:10.1177/0146167204271303.

Hill, S. E., \& Buss, D. M. (2008). The evolutionary psychology of envy. In R. Smith (Ed.) Envy: Theory and research (pp. 60-70). New York: Oxford University Press. http://homepage.psy. utexas.edu/homepage/group/busslab/pdffiles/evolution\%20of\%20envy.pdf. Accessed 17 Dec 2014.

Hill, K., \& Hurtado, A. M. (1996). Ache life history: The ecology and demography of a foraging people. New York: Aldine De Gruyter. http://www.abebooks.com/Ache-Life-History-EcologyDemography-Foraging/6136325563/bd. Accessed 17 Dec 2014.

Hill, S. E., DelPriore, D., \& Major, B. (2013). An evolutionary psychological perspective on happiness. In I. Boniwell \& S. David (Eds.) Oxford handbook of happiness (pp. 875-886). New York: Oxford University Press. http://www.axon.es/axon/LibroFicha.asp?Libro=94159\&T=T HE+OXFORD+HANDBOOK+OF+HAPPINESS. Accessed 17 Dec 2014.

Holder, M. D., \& Coleman, B. (2009). The contribution of social relationships to children's happiness. Journal of Happiness Studies, 10, 329-349. doi:10.1007/s10902-007-9083-0.

Homans, G. C. (1958). Social behavior as exchange. American Journal of Sociology, 63, 597-606. http://www.jstor.org/stable/2772990. Accessed 17 Dec 2014.

Hopcke, R. H., \& Rafaty, L. (1999). Straight women, gay men: Absolutely fabulous friendships. Berkley: Wildcat Canyon Press. http://books.google.com/books/about/Straight_Women_Gay_ Men.html?id=MlcUCx8XuBYC. Accessed 17 Dec 2014.

Hussong, A. M. (2000). Perceived peer context and adolescent adjustment. Journal of Research on Adolescence, 10, 187-224. doi:10.1207/SJRA1004_02.

Kaplan, D. L., \& Keys, C. B. (1997). Sex and relationship variables as predictors of sexual attraction in cross-sex platonic friendships between young and heterosexual adults. Journal of Social and Personal Relationships, 14, 191-206. doi: 10.1177/0265407597142003.

Kemp, M. C. (1995). The Gains from trade and the gains from aid: Essays in international trade theory. London: Routledge. http://www.questia.com/library/104457971/the-gains-from-tradeand-the-gains-from-aid-essays. Accessed 17 Dec 2014.

Kenrick, D. T., Neuberg, S. L., Griskevicius, V., Becker, D. V., \& Schaller, M. (2010). Goal driven cognition and function behavior: The fundamental-motives framework. Current Directions in Psychological Science, 19, 63-67. doi:10.1177/0963721409359281.

Larson, R., Mannell, R., \& Zuzanek, J. (1986). Daily well-being of older adults with friends and family. Psychology and Aging, 1, 117-126. http://www.ncbi.nlm.nih.gov/pubmed/3267387. Accessed 17 Dec 2014.

Lassek, W. D., \& Gaulin, S. J. C. (2008). Waist-hip ratio and cognitive ability: Is gluteofemoral fat a privileged store of neurodevelopmental resources? Evolution and Human Behavior, 29, 26-34. doi:10.1016/j.evolhumbehav.2007.07.005.

Lassek, W. D., \& Gaulin, S. J. C. (2009). Costs and benefits of fat-free muscle mass in men: Relationship to mating success, dietary requirements, and native immunity. Evolution and Human Behavior, 30, 322-328. doi:10.1016/j.evolhumbehav.2009.04.002.

Laursen, B. (1995). Conflict and social interaction in adolescent relationships. Journal of Research on Adolescence, 5, 55-70. doi:10.1207/s15327795jra0501_3.

Lefkowitz, E. S., Boone, T. L., \& Shearer, C. L. (2004). Communication with best friends about sex-related topics during emerging adulthood. Journal of Youth and Adolescence, 33, 339-351. doi:10.1023/B:JOYO.0000032642.27242.c1.

Lehmiller, J. J., Vanderdrift, L. E., \& Kelly, J. R. (2011). Sex differences in approaching friends with benefits relationships. Journal of Sex Research, 48, 275-284. doi:10.1080/00224491003721694. 
Lempers, J. D., \& Clark-Lempers, D. S. (1993). A functional comparison of same-sex and opposite-sex friendships during adolescence. Journal of Adolescent Research, 8, 89-108. doi:10.1177/074355489381007.

Lewis, D. M. G., Conroy-Beam, D., Al-Shawaf, L., Raja, A., DeKay, T., \& Buss, D. M. (2011). Friends with benefits: The evolved psychology of same- and opposite-sex friendship. Evolutionary Psychology, 9, 543-563. http://www.epjournal.net/articles/friends-with-benefits-theevolved-psychology-of-same-and-opposite-sex-friendship/. Accessed 17 Dec 2014.

Lewis, D. M. G., Al-Shawaf, L., Conroy-Beam, D., Asao, K., \& Buss, D. M. (2012). Friends with benefits II: Mating activation in cross-sex friendships as a function of sociosexual orientation and relationship status. Personality and Individual Differences, 53, 622-628. doi:10.1016/j. paid.2012.04.040.

Li, N. P., Bailey, J. M., Kenrick, D. T., \& Linsenmeier, J. A. W. (2002). The necessities and luxuries of mate preferences: Testing the tradeoffs. Journal of Personality and Social Psychology, 82, 947-955. doi:10.1037/0022-3514.82.6.947.

Lu, L. (1995). The relationship between subjective well-being and psychosocial variables in Taiwan. Journal of Social Psychology, 135, 351-357. http://www.ncbi.nlm.nih.gov/pubmed/7650933. Accessed 17 Dec 2014.

Lu, L. (1999). Personal and environmental causes of happiness. Journal of Social Psychology, 139, 79-90. doi:10.1080/00224549909598363.

Malone, J. (1980). Straight women/gay men: A special relationship. New York: Dial Press. http:// www.amazon.com/Straight-women-gay-men-relationship/dp/0803781741.

Milton, K. (1999). A hypothesis to explain the role of meat-eating in human evolution. Evolutionary Anthropology: Issues, News, and Reviews, 8, 11-21. doi:10.1002/(SICI)15206505(1999)8:1<11::AID-EVAN6>3.0.CO;2-M

Mongeau, P. A., Ramirez, A., \& Vorell, M. (2003). Friends with benefits: Initial explorations of sexual, non-romantic, relationships. Unpublished manuscript, Arizona State University at Tempe.

Monsour, M. (2002). Women and men as friends: Relationships across the life span in the 21st century. Mahwah, NJ: Erlbaum.

O'Meara, J. D. (1989). Cross-sex friendship: Four basic challenges of an ignored relationship. Sex Roles, 21, 525-543. doi:10.1007/BF00289102.

Penke, L., \& Asendorpf, J. B. (2008). Beyond global sociosexual orientations: A more differentiated look at sociosexuality and its effects on courtship and romantic relationships. Journal of Personality and Social Psychology, 95(6), 1113-1135. doi:10.1037/0022-3514.95.5.1113.

Rose, S. M. (1985). Same- and cross-sex friendships and the psychology of homosociality. Sex Roles, 12, 63-74. doi:10.1007/bf00288037.

Russell, E. M., DelPriore, D. J., Butterfield, M. E., \& Hill, S. E. (2013). Friends with benefits, but without the sex: Straight women and gay men exchange trustworthy mating advice. Evolutionary Psychology, 11, 132-147. http://www.epjournal.net/articles/friends-with-benefitsbut-without-the-sex-straight-women-and-gay-men-exchange-trustworthy-mating-advice/. Accessed 17 Dec 2014.

Shackelford, T. K., \& Buss, D. M. (1996). Betrayal in mateships, friendships, and coalitions. Personality and Social Psychology Bulletin, 22, 1151-1164. doi:10.1177/01461672962211006.

Simpson, J. A., \& Gangestad, S. W. (1991). Individual differences in sociosexuality: Evidence for convergent and discriminant validity. Journal of Personality and Social Psychology, 60, 870-883. doi:10.1037/0022-3514.60.6.870.

Singh, R., \& Ho, S. Y. (2000). Attitudes and attraction: A new test of the attraction, repulsion and similarity-dissimilarity asymmetry hypotheses. British Journal of Social Psychology, 39, 197-211. doi:10.1348/014466600164426.

Sullivan, H. S. (1953). The interpersonal theory of psychiatry. New York: Norton. http://www. amazon.com/Interpersonal-Theory-Psychiatry-Harry-Sullivan/dp/0393001385. Accessed 17 Dec 2014.

Swain, S. O. (1992). Men's friendship with women: Intimacy, sexual boundaries, and the informant role. In P. Nardi (Ed.), Men's friendships (pp. 153-171). Newbury Park: Sage. http:// www.uk.sagepub.com/books/Book3359/toc. Accessed 17 Dec 2014. 
Tooby, J., \& Cosmides, L. (1996). Friendship and the banker's paradox: Other pathways to the evolution of adaptations for altruism. In W. G. Runciman, J. M. Smith, \& R. I. M. Dunbar (Eds.), Evolution of social behavior patterns in primates and man (Vol. 88, pp. 119-143). New York: Oxford University Press. http://www.cep.ucsb.edu/papers/friendship.pdf. Accessed 17 Dec 2014.

Tooby, J., \& DeVore, I. (1987). The reconstruction of hominid behavioral evolution through strategic modeling. In W. G. Kinzey (Ed.), The evolution of human behavior: Primate models (pp. 183-237). New York: SUNY Press. http://www.cep.ucsb.edu/papers/Reconst.pdf. Accessed 17 Dec 2014.

Trivers, R. L. (1971). The evolution of reciprocal altruism. Quarterly Review of Biology, 46, 35-57. http://www.jstor.org/stable/2822435. Accessed 17 Dec 2014.

Trivers, R. L. (1972). Parental investment and sexual selection. In B. Campbell (Ed.), Sexual selection and the descent of man, 1871-1971 (pp. 136-179). Chicago: Aldine. http://www4.nau.edu/ shustercourses/BIO\%20698/Literature/Trivers\%201972.pdf. Accessed 17 Dec 2014.

Vigil, J. M. (2007). Asymmetries in the friendship preferences and social styles of men and women. Human Nature, 18, 143-161. doi:10.1007/s12110-007-9003-3.

Wilson, M., \& Daly, M. (1992). Who kills whom in spouse killings?: On the exceptional sex ratio of spousal homicides in the United States. Criminology, 30, 189-215. doi:10.1111/j.1745-9125.1992.tb01102.x.

Wilson, M., \& Daly, M. (1996). Male sexual proprietariness and violence against wives. Current Directions in Psychological Science, 5, 2-7. http://www.jstor.org/stable/20182377. Accessed 17 Dec 2014.

Wilson, M., \& Daly, M. (1998). Lethal and nonlethal violence against wives and the evolutionary psychology of male sexual proprietariness. In R. E. Dobash \& R. P. Dobash (Eds.), Rethinking violence against women. Thousand Oaks: Sage http://www.flyfishingdevon.co.uk/salmon/ year3/psy364sexual-selection/daly-wilson-1998.pdf. Accessed 17 Dec 2014. 